\title{
Assessment of a Potential Role of Dickeya dadantii DSM 18020 as a Pectinase Producer for Utilization in Poultry Diets Based on in silico Analyses
}

\author{
Dana K. Dittoe', Ravi D. Barabote'2, Michael J. Rothrock ${ }^{3}$ and Steven C. Ricke ${ }^{1 *}$ \\ ${ }^{1}$ Department of Food Science and Center for Food Safety, University of Arkansas, Fayetteville, AR, United States, \\ ${ }^{2}$ Department of Biological Sciences, University of Arkansas, Fayetteville, AR, United States, ${ }^{3}$ Egg Safety and Quality \\ Research Unit, U.S. National Poultry Research Center, United States Department of Agriculture-Agricultural Research \\ Service (USDA-ARS), Athens, GA, United States
}

\section{OPEN ACCESS}

Edited by: Andrea Gianotti,

University of Bologna, Italy

Reviewed by:

Sébastien Bontemps-Gallo, Institut Pasteur de Lille, France

Byron Brehm-Stecher, lowa State University, United States

Richard Ducatelle,

Ghent University, Belgium

*Correspondence: Steven C. Ricke sricke@uark.edu

Specialty section: This article was submitted to

Food Microbiology, a section of the journal

Frontiers in Microbiology

Received: 31 May 2019 Accepted: 30 March 2020

Published: 23 April 2020

Citation:

Dittoe DK, Barabote RD, Rothrock MJ and Ricke SC (2020) Assessment of a Potential Role of Dickeya dadantii DSM 18020 as a Pectinase Producer for Utilization in Poultry Diets Based on in silico Analyses. Front. Microbiol. 11:751. doi: 10.3389/fmicb.2020.00751
Currently, the poultry industry has been faced with consumer pressure to utilize only vegetable feedstuffs in poultry diets, eliminate antibiotics from poultry production, and rear poultry in free range systems. To maintain current production standards, the industry must determine ways to enhance nutrient uptake and utilization further. One possible solution is the supplementation of pectinase, an enzyme that degrades pectin within the cell walls of plants, in poultry diets. Therefore, the objective of the current study was to determine the potential role of a pectinase producer, Dickeya dadantii DSM 18020, as a commercially utilized pectinase producer in poultry diets against other known pectinase producers, in silico. In the current study, whole genomes of Dickeya dadantii DSM 18020 (Dd18020), D. dadantii 3937 (Dd3937), D. solani IPO 2222 (Ds2222), Bacillus halodurans C-125 (BhC125), and B. subtilis subsp. subtilis str. 168 (Bs168) were compared using bioinformatic approaches to compare the chromosomal genome size, GC content, protein coding genes (CDS), total genes, average protein length (a.a.) and determine the predicted metabolic pathways, predicted pectin degrading enzymes, and pectin-degradation pathways across pectinase producers. Due to insufficient information surrounding the genome of Dd18020 (lack of annotation), the genome of Dd3937, a 99\% identical genome to Dd18020, was utilized to compare pectinaseassociated enzymes and pathways. The results from the current study demonstrated that Dd3937 possessed the most significant proportion of pathways presented and the highest number of pathways related to degradation, assimilation, and utilization of pectin. Also, Dd18020 exhibited a high number of pectinase-related enzymes. Both Dd3937 and Dd2222 shared the pectin degradation I pathway via the EC 3.1.1.11, EC 3.2.1.82, and EC 4.2.2.- enzymes, but did not share this pathway with either Bacillus species. In conclusion, Dd18020 demonstrated the genetic potential to produce multiple pectinase enzymes that could be beneficial to the degradation of pectin in poultry diets. However, for Dd18020 to become a commercially viable enzyme producer for the poultry industry, further research quantifying the pectinase production in vitro and determining the stability of the produced pectinases during feed manufacturing are necessary.

Keywords: free range, pectinase, Dickeya dadantii, all-vegetable diets, in silico 


\section{INTRODUCTION}

Dickeya dadantii, previously classified as Erwinia chrysanthemi by Burkholder (1957), is one the many bacteria responsible for bacterial soft rot disease (Dickeya spp., Erwinia spp., Pectobacterium spp., etc.) that occurs in a wide range of crops (Samson et al., 2005; Toth et al., 2011). The facultative anaerobic, Gram-negative bacilli typically grow at an optimal temperature of $39^{\circ} \mathrm{C}$, but can grow between the ranges of $25-40^{\circ} \mathrm{C}$ (Samson et al., 2005). The typical transmission of $D$. dadantii to plants is through direct contact with contaminated soil (Grenier et al., 2006). Contamination of soil can occur through several vectors such as water (irrigation, runoff, etc.), various insects, and specific agricultural techniques such as plowing (Grenier et al., 2006). Due to the pectinolytic nature of $D$. dadantii, it causes an infection in crops that induces soft rot that can be characterized by the rapid disorganization of the parenchymatous tissues (Hugouvieux-Cotte-Pattat et al., 1996). Although the colonization of plants by soft rot Erwinia is primarily driven by the production of pectic enzymes, the process is multifactorial requiring cellulases, iron assimilation, an Hrp type III secretion system, exopolysaccharides, motility, and proteins involved in resistance against plant defense mechanisms (Barabote et al., 2003; Toth et al., 2003; Ravirala et al., 2007). Due to the capability of $D$. dadantii to produce pectinases, it has the potential to be advantageous to multiple industries.

Pectinases consist of a group of enzymes that hydrolyze pectin present in plant cell walls and exist in higher order plants and microorganisms (Whitaker, 1991). In plants, pectinases are found to enhance cell wall extension (Jayani et al., 2005) and promote softening of specific plant tissues during maturation and later storage (Aguilar and Huirton, 1990; Sakai, 1992). Therefore, pectinases are used to degrade plant materials in multiple food processing techniques such as reducing the time it takes to extract fruit juice from fruit puree (Junwei et al., 2000) and enhancing the clarity in wine (Kobayashi et al., 2001). Currently, pectinase is applied in several processes such as textile processing and bio-scouring of cotton fibers, the degumming and retting of plant bast fibers, wastewater treatment, coffee and tea fermentation, paper and pulp industry, purification of plant viruses, and in animal feed (Sharma et al., 2013). Across industries, pectinases are mass manufactured by utilizing pectinase producing bacteria and fungi. Of such bacteria and fungi, Bacillus and Aspergillus are the most characterized pectinase producers utilized across manufacturing of agricultural and food products (Garg et al., 2016).

Of the many uses of pectinases, the poultry industry would greatly benefit from the addition of pectinases in poultry diets. Recently, consumer pressure has motivated the poultry industry to introduce no antibiotic ever (NAE), all -vegetable fed broilers (Weil, 2017). In addition, there has also been an increased demand for free range poultry and forage feeding. In efforts to utilize locally available feed sources, sectors of the poultry industry have initiated forage feeding, pasture farming, or supplementary feeding regimens (Buchanan et al., 2007). With the move to all -vegetable diets and forage feeding, broiler diets may contain an increased concentration of cereals containing non-starch polysaccharides (NSPs) in their endosperm (Broz and Beardsworth, 2002). Poultry are unable to produce many of the enzymes necessary to degrade NSP's and broiler performance is decreased due to the impairment of digestive enzymes, decreased nutrient absorption, and increase in viscous excreta (Broz and Beardsworth, 2002).

The supplementation of diets with pectin has specifically resulted in the decrease of growth rate, decrease in feed efficiency, increase in feed intake, increase in sticky droppings, and overgrowth of Clostridium species (Wagner and Thomas, 1977, 1978; Ricke et al., 1982). More recently, research has demonstrated that pectinases have the ability to degrade pectin more readily in poultry diets alone and in combination with other NSP-hydrolyzing enzymes. In addition, the supplementation of pectinase, cellulase, or hemicellulase alone in poultry diets has proven to be less effective than their combination on improving poultry performance (Tahir et al., 2005, 2006).

Currently, the major sources of NSP-containing plant material within poultry diets is corn and soybean meal (Pierson et al., 1980; Chesson, 2001). However, due to the increasing demand for corn and soybean meal from the swine industry and other sectors, the poultry industry has explored alternative sources of carbohydrates. Such sources are wheat, barley, and lupins (Australia) which contain high amounts of NSPs compared to those contained in corn and soybean meal, specifically pectin (Bailoni et al., 2005; Leeson, 2008; Kim et al., 2011).

Therefore, there is a need for a wide variety of enzymes, especially those that break down plant material that poultry are unable to utilize on their own due to the vast differences in plant composition. For example, of the pectins contained within the cell wall of plants vary in amount and in the physiochemical properties such as structural differences among the types of plants and fruits (Kamnev et al., 1998). Pectin structure consists of an $\alpha(1-4)$-linked polygalacturonans with varying chain lengths, intermittent rhamnosyl residues, and other potential structural variations (Selvendran, 1985; Piknik, 1990; King, 1993). Further, there are currently no products on the market that solely target the complex structures of pectins, especially those contained in lupins (Kim et al., 2011). Pectin contain galactose residues of the polygalacturonans that are methyl-esterfied at C-6, which protects the substrate from the access of pectinases (Ali et al., 2005). Further, the in vitro supplementation of pectin methyl esterase and polygalacturonase in combination with ground dehulled lupins (Lupinus angustifolius in $70 \mathrm{~mL}$ acid buffer) reduced the length of pectin chains by $65 \%$ and molecular weight of pectin by $56 \%$ (Ali et al., 2005). As such, it is imperative to identify bacterial enzyme sources capable of producing a wide variety of pectinases for potential commercial development.

Pectinases have been provided in poultry diets in addition to other enzymes to enhance nutrient digestibility of broilers and other poultry species. Previous research has demonstrated that the use of pectinases in an enzyme cocktail has the capability to reduce the viscosity of the feed, release nutrients through the hydrolysis of non-biodegradable fibers or those blocked by these fibers and reduce the total amount of excreted 
feces (Jayani et al., 2005). Therefore, the overall objectives of the current study were to determine if the genome of Dickeya dadantii DSM 18020 (NZ_CP023467.1) encodes pectinases, if, in turn, those pectinases are comparable to those currently utilized in the poultry industry, and if $D$. dadantii would make a suitable alternative source of novel pectinases to those bacteria currently used commercially to produce pectinases.

\section{MATERIALS AND METHODS}

\section{Genomic Data Retrieval}

In the current study, genomic data was accessed and collected from the National Center for Biotechnology Information (NCBI) on December 7, 2018 (O'Leary et al., 2016). The genomic data for Dickeya dadantii DSM 18020 (NZ_CP023467.1), D. dadantii 3937 (NC_014500.1; Glasner et al., 2011), D. solani IPO 2222 (NZ_CP015137.1; Pédron et al., 2014), Bacillus subtilis subsp. subtilis str. 168 (NC_000964.3; Kunst et al., 1997; Barbe et al., 2009; Belda et al., 2013; Borriss et al., 2018) and B. halodurans C-125 (NC_002570.2; Takami et al., 2000), was utilized in the current study to compare novel pectinase homologs
(Dickeya spp.) to known industrialized pectinase producers (Bacillus spp.) and their associated metabolic pathways.

\section{Genomic Relation Across Pectinase Producers}

Genomic data that was retrieved from NCBI was utilized to compare the genomic characteristics of Dickeya dadantii DSM 18020 (Dd18020), D. dadantii 3937 (Dd3937), D. solani IPO 2222 (Ds2222), Bacillus subtilis subsp. subtilis str. 168 (Bs168), and B. halodurans C-125 (BhC125). Genomic characteristics that were compared among bacterium were chromosomal genome size $(\mathrm{Mb})$, Guanidine to Cytosine content (GC Content; $\%)$, protein-coding genes (CDS), total genes, and average protein length (a.a).

Dd3937, a wild-type strain originally isolated from Saintpaulia ionantha, is most commonly used as a model organism for soft rot pathogenesis since the 1980's (Glasner et al., 2011). As Dd3937 is a known model organism, the authors wanted to explore the candidacy of a more recently discovered strain, DSM 18020. Dd18020 was recently isolated from Pelargonium capitum in Comoros and deposited to the Leibniz Institute DSMZ-German Collection of Microorganisms and Cell

TABLE 1 | Comparative genomic information of five pectinase producing bacteria.

\begin{tabular}{|c|c|c|c|c|c|c|c|c|}
\hline Bacterium & $\begin{array}{c}\text { NCBI accession } \\
\text { number }\end{array}$ & $\begin{array}{l}\text { Chromosomal } \\
\text { genome } \\
\text { size (Mb) }\end{array}$ & $\begin{array}{c}\text { GC } \\
\text { content }\end{array}$ & $\begin{array}{l}\text { Protein } \\
\text { coding genes } \\
\text { (CDS) }\end{array}$ & $\begin{array}{c}\text { Total } \\
\text { genes }\end{array}$ & $\begin{array}{c}\text { Average } \\
\text { protein length } \\
\text { (a.a.) }\end{array}$ & $\begin{array}{l}\text { Isolated } \\
\text { from }\end{array}$ & References \\
\hline $\begin{array}{l}\text { Dickeya dadantii } \\
\text { DSM } 18020\end{array}$ & NZ_CP023467.1 & 5.00 & $56.40 \%$ & 4,271 & 4,531 & 326 & $\begin{array}{l}\text { Pelargonium } \\
\text { capitatum }\end{array}$ & Cheng et al., 2017 \\
\hline $\begin{array}{l}\text { Dickeya dadantii } \\
3937\end{array}$ & NC_014500.1 & 4.92 & $56.30 \%$ & 4,244 & 4,485 & 323 & $\begin{array}{c}\text { Saintpaulia } \\
\text { ionantha }\end{array}$ & Glasner et al., 2011 \\
\hline $\begin{array}{l}\text { Dickeya solani } \\
\text { IPO } 2222\end{array}$ & NZ_CP015137.1 & 4.92 & $56.20 \%$ & 4,132 & 4,329 & 339 & $\begin{array}{l}\text { Solanum } \\
\text { tuberosum }\end{array}$ & Khayi et al., 2016 \\
\hline $\begin{array}{l}\text { Bacillus subtilis } \\
\text { subsp. subtilis str. } \\
168\end{array}$ & NC_000964.3 & 4.22 & $43.50 \%$ & 4,237 & 4,871 & 290 & $\begin{array}{l}\text { Mutant } \\
\text { strain of } \\
\text { B. subtilis } \\
\text { Marburg } 1\end{array}$ & $\begin{array}{l}\text { Kunst et al., 1997; } \\
\text { Belda et al., 2013; } \\
\text { Borriss et al., 2018; } \\
\text { Barbe et al., } 2009\end{array}$ \\
\hline $\begin{array}{l}\text { Bacillus } \\
\text { halodurans } \\
\text { C-125 }\end{array}$ & NC_002570.2 & 4.20 & $43.70 \%$ & 3,950 & 4,134 & 298 & Soil & $\begin{array}{l}\text { Nakasome et al., } \\
\text { 2000; Takami and } \\
\text { Horikoshi, 2000; } \\
\text { Takami et al., } 2000\end{array}$ \\
\hline
\end{tabular}

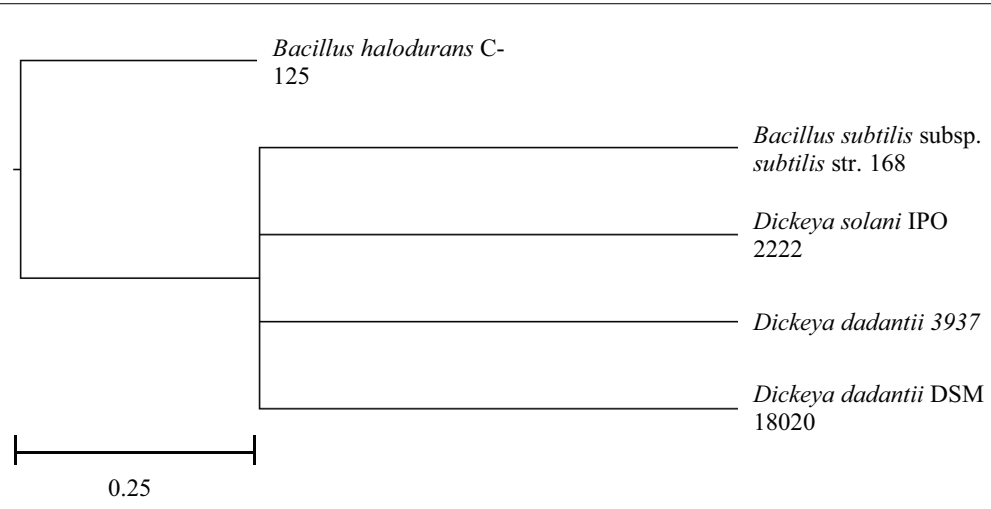

FIGURE 1 | Rooted phylogenic tree of five pectinase-producing bacteria after multiple alignment in MAUVE. 
Culture (Braunschweig, Germany). The authors were particularly motivated to choose $\operatorname{Dd} 18020$ as the candidate pectinase producer in the current study as there are no current Nagoya Protocol restrictions to its use, it is obtainable through multiple collections of plant-associated bacteria, and has a complete genome assembly available on NCBI. Therefore, Dd18020 can be annotated (genome), purchased, and applied in research or industrial use consistently and without restrictions.

However, due to the absence of Dd18020 in several databases, Dd18020 and Dd3937 were compared against one another by comparing syntany and homogeneity. Syntany was explored using the progressive MAUVE whole genome alignment (Darling et al., 2004). Homogeneity was investigated using Web Blast on NCBI (Altschul et al., 1990). As other research has utilized reference genomes to identify close proximity to the target bacteria or organism (Tyson et al., 2004; Iverson et al., 2012; Wrighton et al., 2012; Albertsen et al., 2013; Sharon et al., 2013), the comparison of Dd18020 and Dd3937 was utilized to validate if Dd3937 was an appropriate reference genome for Dd18020. Therefore, further genomic comparisons were done in the absence of Dd18020, with Dd3937 in its stead. In addition, a rooted phylogenetic tree was constructed from the output obtained from progressiveMAUVE whole genome alignment of Dd18020, Dd3937, Ds2222, Bs168, and BhC125 (Darling et al., 2010).

\section{Predicted Pathways Across Pectinase Producers}

In the current study, genomes of Dd3937, Ds2222, Bs168, and BhC125 were compared in MetaCyc (MetaCyc 22.5;
Caspi et al., 2014) to evaluate the protein and pathway similarities between genomes of the four pectinase producers. Numerical comparisons were performed in Microsoft Excel for Office 365 MSO (16.0.11601.20174; Microsoft, Redmond, WA, United States) to highlight the numerical difference in pathways between the four pectinase producers utilized in the current study.

\section{Predicted Pectin-Related Enzymes Across Pectinase Producers}

The list of proteins and enzymes encoded in the genomes of Dd18020, Dd3937, Ds2222, Bs168, and BhC125 was retrieved from NCBI (O'Leary et al., 2016) and utilized to determine the pectin-related proteins and enzymes encoded. Proteins encoded in the genome of the pectinase producers were aligned in MegaX (Kumar et al., 2018) using ClustalW (Thompson et al., 1994) where Maximum Likelihood was utilized to produce a rooted phylogenetic tree. In addition, Metacyc was subsequently utilized to compare pectinase related enzymes and genes across the four pectinase producers: Dd3937, Ds2222, Bs168, and BhC125. The top eleven related proteins were chosen for comparison in the current study.

\section{Pectinase Pathway}

As Dd18020 is less studied, Dd3937 was chosen to elucidate the pectin-related pathways. MetaCyc 22.5 was utilized to determine the pathways of Dd3937. Dd3937 was subsequently compared to the other pectinase producers utilized in the current study: Ds2222, Bs168, and BhC125.

TABLE 2 | Direct comparison of Dickeya dadantii DSM 18020 and 3937 complete genomes.

\begin{tabular}{|c|c|c|c|c|c|c|}
\hline Description & Max score & Total score & Query cover & $E$-value & Ident & Accession \\
\hline Dickeya dadantii 3937, complete genome & $1.661 e+05$ & $9.161 e+06$ & $91 \%$ & 0.0 & $99 \%$ & NC_014500.1 \\
\hline
\end{tabular}

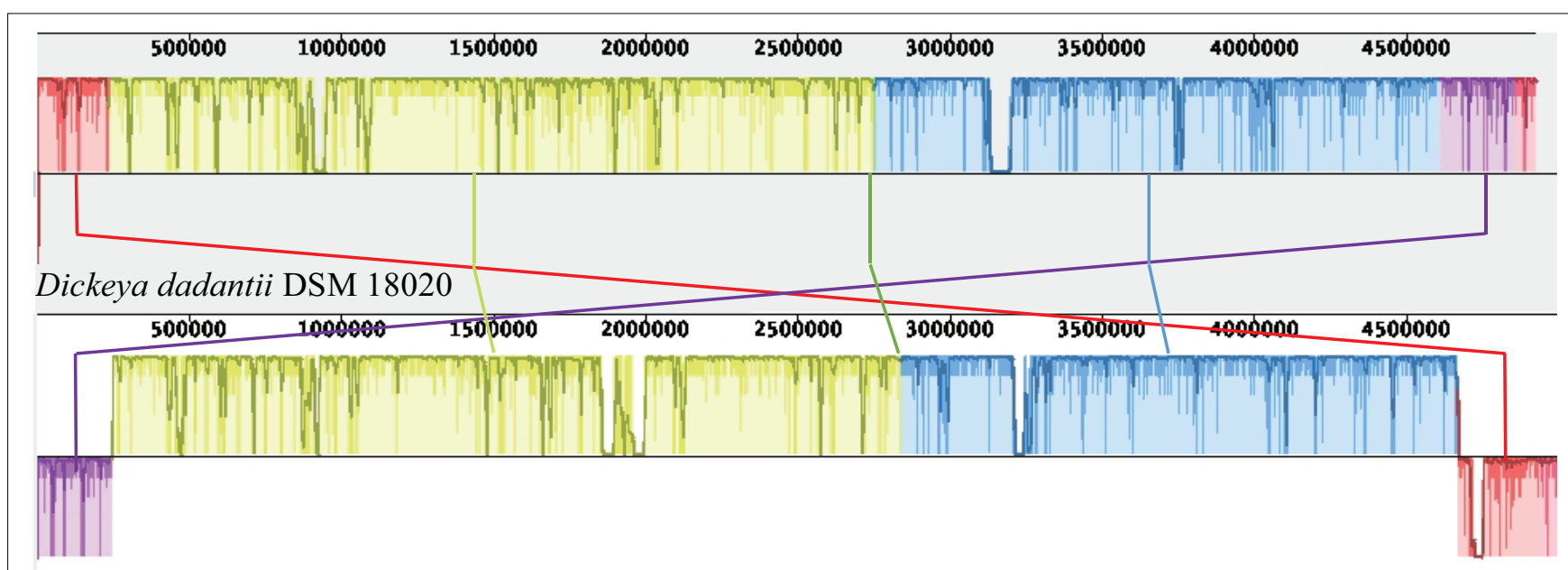

Dickeya dadantii 3937

FIGURE 2 | Synteny analysis of Dickeya dadantii DSM 18020 (NZ_CP023467.1) and 3937 (NC_014500.1). Synteny analysis was performed using MAUVE whole genome alignment. Arrows indicate the regions that are located in different positions in both genomes. 
TABLE 3 | Analysis of metabolic pathways in the genomes of four pectinase producing bacteria.

\section{Dickeya dadantii 3937 Dickeya solani IPO 2222 Bacillus subtilis subsp. Bacillus halodurans C-125}

Pathway class ${ }^{a}$

NC_014500.1

NZ_CP015137.1 subtilis str. 168

Biosynthesis

Amine and polyamine biosynthesis

Amino acid biosynthesis

Aminoacyl-tRNA charging

Aromatic compound biosynthesis

Carbohydrate biosynthesis

Cell Structure biosynthesis

Cofactor, prosthetic group, electron carrier, and vitamin biosynthesis

Fatty acid and lipid biosynthesis

Hormone biosynthesis

Metabolic regulator biosynthesis

Nucleoside and nucleotide biosynthesis

Other biosynthesis

Secondary metabolite biosynthesis

Storage compound biosynthesis

Degradation/utilization/assimilation

Alcohol degradation

Aldehyde degradation

Amine and polyamine degradation

Amino acid degradation

Aromatic compound degradation

C1 compound utilization and assimilation

Carbohydrate degradation

Carboxylate degradation

Chlorinated compound degradation

Cofactor, prosthetic group, electron carrier degradation

Degradation/utilization/assimilation - other

Fatty acid and lipid degradation

Hormone degradation

Inorganic nutrient metabolism

Nucleoside and nucleotide degradation

Polymeric compound degradation

Protein degradation

Secondary metabolite degradation

Generation of precursor metabolite and

energy

Signal transduction pathways

Total

\begin{tabular}{|c|c|c|c|}
\hline 178 & 164 & 155 & 151 \\
\hline 2 & 4 & 3 & 4 \\
\hline 22 & 24 & 28 & 32 \\
\hline 1 & 1 & 2 & 3 \\
\hline 4 & 4 & 4 & 3 \\
\hline 14 & 12 & 8 & 6 \\
\hline 6 & 5 & 2 & 2 \\
\hline 51 & 41 & 44 & 43 \\
\hline 13 & 15 & 11 & 10 \\
\hline 3 & 1 & 0 & 0 \\
\hline 2 & 2 & 2 & 1 \\
\hline 21 & 18 & 19 & 18 \\
\hline 0 & 0 & 0 & 0 \\
\hline 4 & 4 & 8 & 3 \\
\hline 0 & 0 & 0 & 0 \\
\hline 106 & 98 & 97 & 94 \\
\hline 3 & 3 & 3 & 2 \\
\hline 2 & 3 & 2 & 0 \\
\hline 3 & 6 & 4 & 7 \\
\hline 14 & 13 & 21 & 19 \\
\hline 2 & 3 & 1 & 3 \\
\hline 3 & 2 & 2 & 3 \\
\hline 17 & 20 & 20 & 18 \\
\hline 12 & 14 & 13 & 11 \\
\hline 1 & 0 & 0 & 0 \\
\hline 0 & 0 & 0 & 0 \\
\hline 2 & 1 & 0 & 0 \\
\hline 4 & 4 & 3 & 3 \\
\hline 0 & 0 & 0 & 0 \\
\hline 13 & 7 & 5 & 5 \\
\hline 15 & 7 & 9 & 10 \\
\hline 5 & 6 & 4 & 3 \\
\hline 0 & 0 & 0 & 0 \\
\hline 14 & 16 & 10 & 8 \\
\hline 16 & 18 & 18 & 18 \\
\hline 0 & 0 & 17 & 0 \\
\hline 252 & 234 & 252 & 226 \\
\hline
\end{tabular}

${ }^{a}$ Green shading represents the highest incidence of pathways between the four pectinase producing bacteria, with white representing the lowest incidence of pathways between the four pectinase producing bacteria.

\section{RESULTS}

In relation to the genomic make-up of the pectinase producers, all D. dadantii species, Dd18020 and Dd3937, and Ds2222 were more similar in their genome size $(5.00,4.92$, and $4.92 \mathrm{Mb}$, respectively), GC content $(56.40,56.30$, and $56.20 \%$, respectively) and average protein-coding length $(326,323,339$ a.a., respectively) than the size, GC content, and average protein-coding length of the two Bacillus species (4.22 and 4.20 Mb, 43.50 and $43.70 \%$, and 290 and 298 a.a., respectively, Table 1). All bacteria in the current study possessed similar levels of proteins and genes, with BhC125 having the fewest number of proteins and genes (3,950 CDS and 4,134 total genes). In addition, both bacilli possessed smaller average protein lengths than the Dickeya species. The differences in size, GC content, average proteincoding length, proteins, and genes may be attributed to Dickeya and Bacillus species belonging to different phyla 
TABLE 4 | Pectin degradation related enzymes produced by Dickeya dadantii DSM 18020.

\begin{tabular}{lcl}
\hline NCBI accession number & Protein length & Protein description \\
\hline WP_038911228.1 & 576 & Pectate lyase \\
WP_038912610.1 & 551 & Pectin acetylesterase \\
WP_038901807.1 & 366 & Pectinesterase A \\
WP_013318064.1 & 110 & MULTISPECIES: pectin \\
WP_013316284.1 & 315 & degradation protein kdgF \\
WP_038911625.1 & 344 & Pectate lyase \\
WP_013319746.1 & 374 & Pectate lyase \\
WP_013319745.1 & 375 & Pectate lyase \\
WP_038911695.1 & 392 & Pectate lyase \\
WP_038901806.1 & 392 & Pectate lyase \\
WP_038901804.1 & 404 & Pectate lyase \\
WP_038911484.1 & 425 & Pectate lyase \\
WP_038911249.1 & 543 & Pectate lyase \\
\hline
\end{tabular}

(Proteobacteria and Firmicutes, respectively) (Figure 1, Galperin, 2015; Lockwood et al., 2019).

Due to the paucity of literature and available genomic research concerning Dd18020, comparison of Dd18020 and Dd3937 genomic information was performed in Web BLAST (Table 2). The results of the global alignment in Web BLAST revealed that the two genomes were a $99 \%$ match and therefore the genome of Dd3937 was sufficient to compare to other pectinase producers in lieu of Dd18020. The E-value, maximum score, and maximum identity of Dd18020 and Dd3937 genomes were $0.0,1.661 \mathrm{e}+05$, and $99 \%$, respectively, indicating that the local coverage was high. The total metrics were also relatively high, with a total score and query coverage of $9.161 \mathrm{e}+06$ and $91 \%$, respectively. In addition, synteny was explored between Dd18020 and Dd3937 (Figure 2). The Dd18020 genome is highly syntenic with the Dd3937 genome, exhibiting only two disruptions. One region of about $250 \mathrm{~kb}$ is present at different locations in both chromosomes (location 4.6-4.85 Gb in Dd18020 and 0-242 kb in Dd3937). A second region in Dd18020 chromosome is split into two regions. The first region of $\mathrm{Dd} 18020$ is at position 0 to $228 \mathrm{~kb}$ and the second region at position $4.85-4.92 \mathrm{~Gb}$.

The metabolic pathways of the four pectinase producers were compared in MetaCyc 22.5, with Dd3937 representing Dd18020. The pathways did differentiate in several ways (Table 3). In all, Dd3937 and Bs168 exhibited the highest representation of pathways, however, Dd3937 had the highest proportion of total pathways presented. In relation to degradation, assimilation, and utilization, Dd3937 possessed the highest number of related pathways. Carbohydrate biosynthesis was present in the highest number (14) in Dd3937 when compared to the three other pectinase producers. Ds2222 had the second highest number of carbohydrate biosynthesis pathways (12) than both Bacillus species (8 and 6); however, when carbohydrate degradation pathways were examined, Dd3937 had the lowest representation of pathways (17), with Ds2222 and Bs168 possessing more carbohydrate degradation pathways (20 and 20, respectively).

Dd18020 was screened for pectinase-related genes by exploring the genome in NCBI (Table 4). The genome of Dd18020 contained 13 identified extracellular pectinaserelated proteins: pectin acetylesterase, pectinesterase A, MULTISPECIES: pectin degradation protein KdgF, and several pectate lyases. The pectin degrading enzymes and proteins

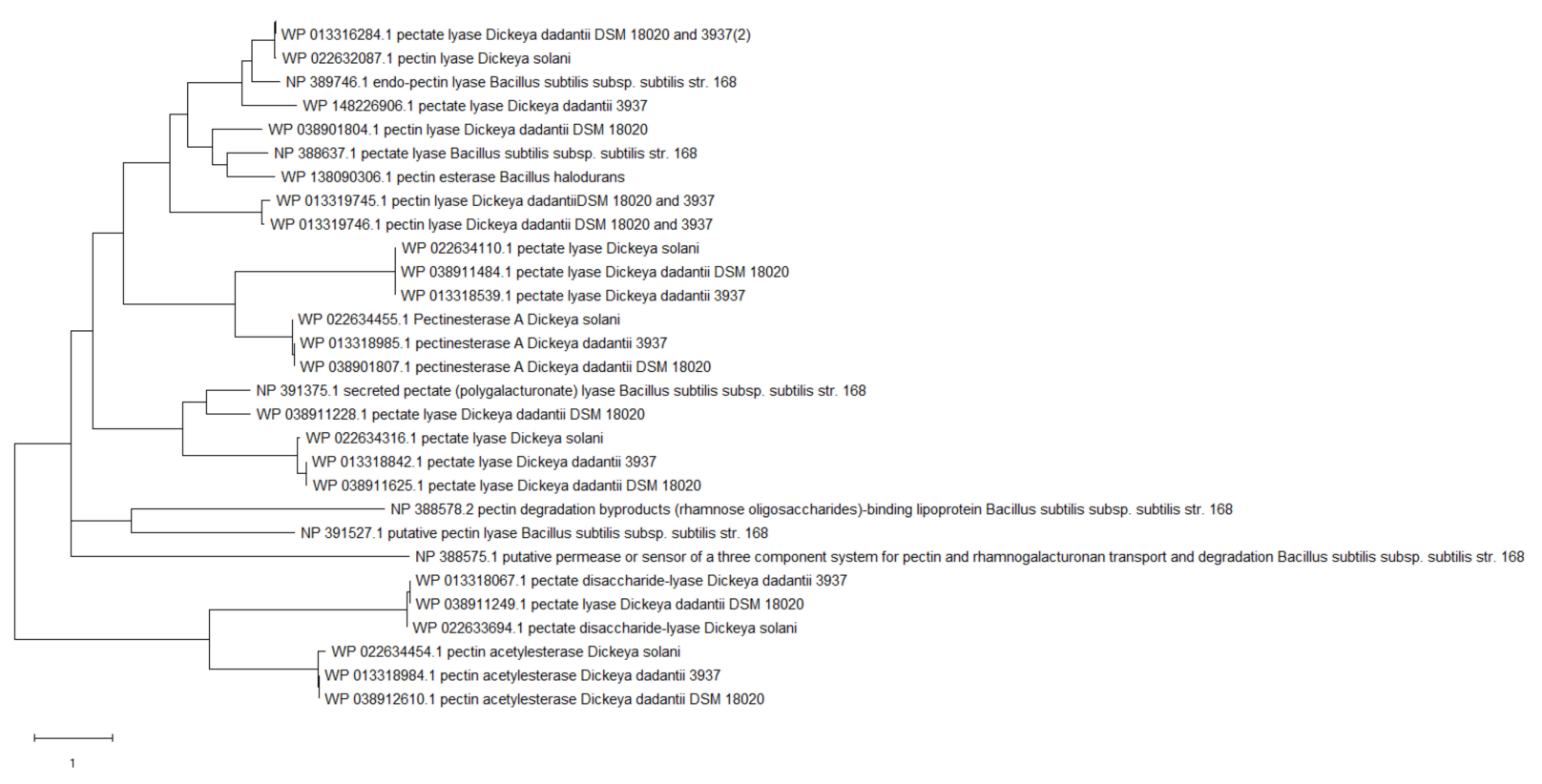

FIGURE 3 | Rooted phylogenic tree of pectin degrading enzymes encoded in the genomes of Dickeya dadantii 18020, D. dadantii 3937, D. solani IPO 2222, Bacillus subtilis subsp. subtilis str. 168, and B. halodurans C-125. Proteins encoded in the genome of the pectinase producers were aligned in MegaX using ClustalW where Maximum Likelihood was utilized to produce a Newick tree. 
encoded in the genome of the five pectinase producers in the current study demonstrated no distinct pattern in genetic divergence (Figure 3). For example, Dd18020, Dd3937, Ds2222, and Bs168 possess the genetic potential to produce pectin lyase which evolutionarily is the most recent with Dd18020, Dd3937, and Ds2222 being a polytomy. Overall, the evolutionary

TABLE 5 | Comparison of key pectinase enzymes between four pectinase producing bacteria.

\begin{tabular}{|c|c|c|c|c|c|}
\hline \multicolumn{2}{|c|}{ Protein homolog } & \multirow{2}{*}{$\begin{array}{l}\begin{array}{l}\text { Dickeya dadantii } \\
\mathbf{3 9 3 7}\end{array} \\
\text { DDA3937_RS15625 }\end{array}$} & \multirow{2}{*}{$\begin{array}{l}\text { Dickeya solani } \\
\text { IPO } 2222 \\
\text { None }\end{array}$} & \multirow{2}{*}{$\begin{array}{l}\text { Bacillus subtilis subsp. } \\
\text { subtilis str. } 168\end{array}$} & \multirow{2}{*}{$\begin{array}{l}\begin{array}{l}\text { Bacillus halodurans } \\
\text { C-125 }\end{array} \\
\text { AYT26_RS19885 }\end{array}$} \\
\hline 1 & Product & & & & \\
\hline & Gene & Pectin acetylesterase & None & $\begin{array}{l}\text { Rhamnogalacturonan } \\
\text { acetylesterase }\end{array}$ & Hypothetical protein \\
\hline \multirow[t]{2}{*}{2} & Product & DDA3937_RS11325 & None & None & AYT26_RS02680 \\
\hline & Gene & $\begin{array}{l}\text { Pectin degradation } \\
\text { protein kdgF }\end{array}$ & None & None & Cupin \\
\hline \multirow[t]{2}{*}{3} & Product & DDA3937_RS15615 & None & Pel & AYT26_RS03755 \\
\hline & Gene & Pectate lyase & None & Pectate lyase & Hypothetical protein \\
\hline \multirow[t]{2}{*}{4} & Product & DDA3937_RS16955 & None & yesO & AYT26_RS05885 \\
\hline & Gene & $\begin{array}{l}\text { Sugar ABC transporter } \\
\text { substrate-binding } \\
\text { protein }\end{array}$ & None & $\begin{array}{l}\text { Pectin degradation } \\
\text { byproducts-binding } \\
\text { lipoprotein }\end{array}$ & Hypothetical protein \\
\hline \multirow[t]{2}{*}{5} & Product & DDA3937_RS19500 & None & None & AYT26_RS19165 \\
\hline & Gene & Pectate lyase & None & None & pectate lyase \\
\hline \multirow[t]{2}{*}{6} & Product & DDA3937_RS11370 & None & ytmA & AYT26_RS16630 \\
\hline & Gene & Pectin acetylesterase & None & Putative hydrolase & Peptidase \\
\hline \multirow[t]{2}{*}{7} & Product & DDA3937_RS02860 & None & pelB & None \\
\hline & Gene & Pectate lyase & None & Pectin lyase & None \\
\hline \multirow[t]{2}{*}{8} & Product & DDA3937_RS11370 & None & ytmA & AYT26_RS16630 \\
\hline & Gene & Pectin acetylesterase & None & Putative hydrolase & Peptidase \\
\hline \multirow[t]{2}{*}{9} & Product & DDA3937_RS09860 & None & ywoF & None \\
\hline & Gene & Pectate lyase & None & Putative pectate lyase & None \\
\hline \multirow[t]{2}{*}{10} & Product & DDA3937_RS11105 & None & pelC & None \\
\hline & Gene & Type III secreted protein & None & Secreted pectate lyase & None \\
\hline \multirow[t]{2}{*}{11} & Product & DDA3937_RS15625 & None & yesY & AYT26_RS19885 \\
\hline & Gene & Pectin acetylesterase & None & $\begin{array}{l}\text { Rhamnogalacturonan } \\
\text { acetylesterase }\end{array}$ & Hypothetical protein \\
\hline
\end{tabular}

A

pectineresterase A:

DDA3937_RS15630

3.1.1.11

a pectin

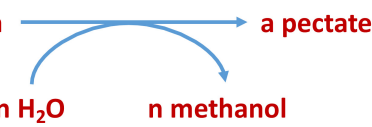

exo-poly-alpha-D-galacturonosidase:

DDA3937_RS20090

exo-poly-alpha-D-galacturonosidase:

DDA3937_RS20095

exo-poly-alpha-D-galacturonosidase:

DDA3937_RS20100

exo-poly-alpha-D-galacturonosidase:

DDA3937_RS05830

3.2.1.82

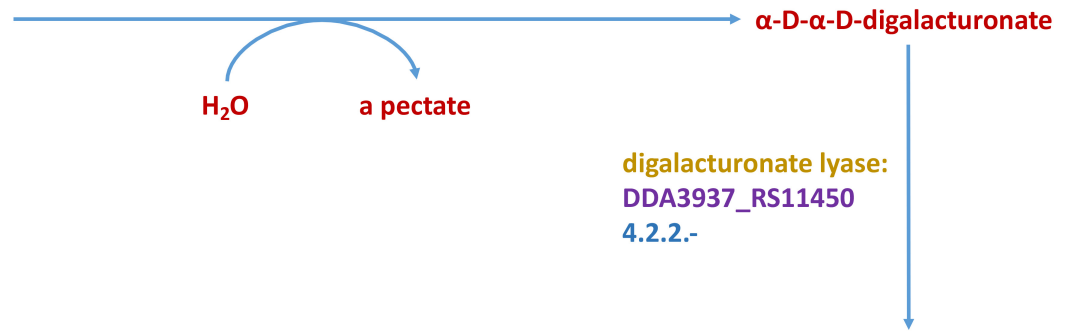

D-galactopyranuronate

4-deoxy-L-threo-hex-4-enopyranuronate degradation

FIGURE 4 | Continued 
B

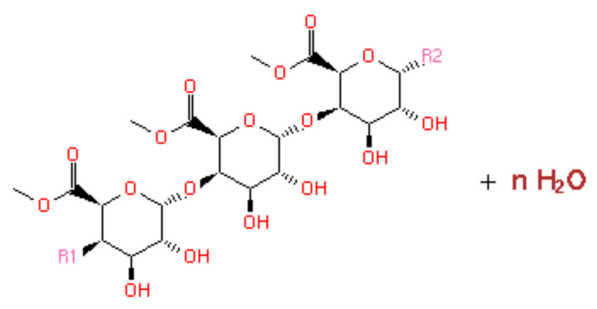

a pectin

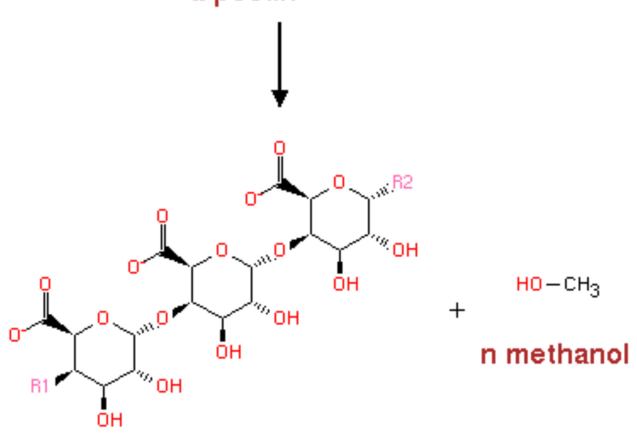

a pectate
C

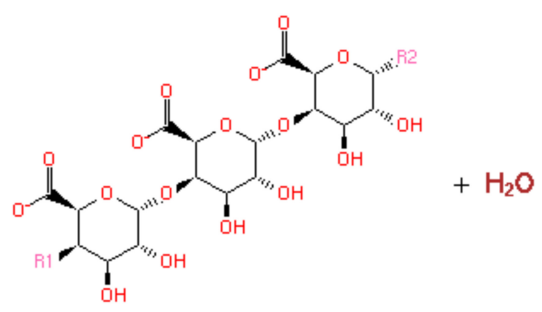

a pectate

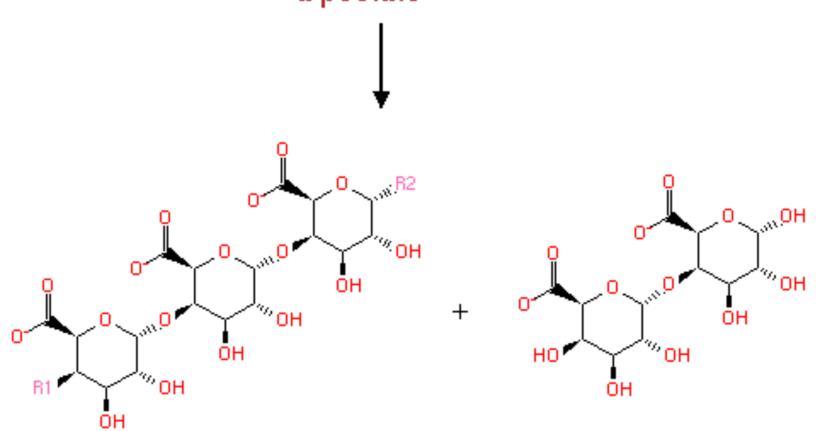

a pectate
$\alpha$-D, $\alpha$-D-digalacturonate

D<smiles>O=C(O)[C@H]1O[C@H](O[C@H]2[C@@H](O)O[C@H](C(=O)O)[C@H](O)[C@H]2O)[C@H](O)[C@@H](O)[C@@H]1O</smiles>

$\alpha$-D-galacturonosy-(1->4)- $\alpha$-D-galacturonate<smiles>CC(C)CC1C[C@@H](O)C(O)OC1C(=O)O</smiles>

D-galactopyranuronate 4-deoxy-L-threo-hex-4-enopyranuronate

FIGURE 4 | Enzymes, genes, and products for pectin degradation in Dickeya dadantii 3937 (A). Pectin is first acted upon by pectinesterase A (3.1.1.11) which yields a pectate and $n$-methanol (B). Pectate is further degraded to $\alpha$-D- $\alpha$-D-digalacturonate by an exo-poly- $\alpha$-D-galacturonosidase (3.2.1.82) with a pectate as a byproduct (C). The $\alpha$-D- $\alpha$-D-digalacturonate is then degraded to D-galactopyranuronate 4-deoxy-L-threo-hex-4-enopyranuronate by the enzyme catalyst digalacturonate lyase (4.2.2.-) (D).

divergence of pectin degrading enzymes is primarily due to the emergence of new proteins and enzymes, rather than the differences between pectinase producing bacteria. Pectin degrading enzymes encoded by Dadantii species were less divergent between one another than those encoded by the Bacilli.
Due to the paucity of genomic research related to Dd18020, Dd3937 was compared to the three other pectinase-producing bacteria in MetaCyc 22.5 (Table 5). The top eleven pectinaserelated enzymes that were shared among pectinase producers are also present in Dd18020 (Tables 4, 5), however, Ds2222 
did not appear to share similar enzymes to either Dd3937 or both Bacillus species. It appears that $D$. dadantii possesses more proteins dedicated to degradation, utilization, and assimilation (105) than Ds2222, Bs168, and BhC125 (97, 95, and 94 proteins, respectively). However, in vitro modeling should be done to quantify the pectinase production of $D$. dadantii compared to other pectinase-producing bacteria.

In addition to comparing the pectinase-related proteins produced by Dd18020 and the four other bacteria utilized in the current study, the metabolic pathways related to pectin degradation were compared simultaneously for shared pectinase related pathways in MetaCyc 22.5. Of the shared pathways, only the two Dickeya species shared similar pathways, EC 3.1.1.11, EC 3.2.1.82, and EC 4.2.2.- (Figure 4A). The presence of shared pathways between the two Dickeya species was relatively surprising, as the genome-encoded pectinaserelated enzyme comparison did not reveal similarities in the proteins encoded by the two Dickeya species. In fact, Ds2222 did not possess similarly coded proteins to that of the other three bacteria (Table 5). However, the metabolic pathway related to pectin degradation I was shared between Dd3937and Ds2222.

Pectinases have been divided into three separate groups dependent on the cleavage site. These three groups of pectinases are comprised of (1) hydrolases consisting of polygalacturonase, PG (EC 3.2.1.15); (2) lyase/trans-eliminases comprising pectin lyase, PNL (EC 4.2.2.10), and pectate lyase, PL (EC 4.2.2.2); and (3) pectinesterase, PE (EC 3.1.1.11) (Yadav et al., 2009; Visser et al., 2004). In the current study, similar pathways (Figures 4A-D) of all categories were observed in Dd18020, Dd3937, and Ds2222.

In the pectin degradation pathway, both Dd3937and Ds2222 possessed the same enzyme, pectinesterase A (EC 3.1.1.11), encoded for by the DDA3937_RS15630 and DSOIPO2222_RS15080 genes (data not shown). In the same pathway, the enzymes and genes of similar relation from Dd3937and Ds2222 were several exo-poly$\alpha$-D-galacturonosidases (EC 3.2.1.82) encoded for by the DDA3937_RS20090, DDA3937_RS20095, DDA3937_RS20100, and DDA3937_RS05830 genes of Dd3937and the DSOIPO2222_RS19410, DSOIPO2222_RS19420, and DSOIPO2222_RS19425 genes of Ds2222. Lastly, in the metabolic pathway EC 4.2.2.-, the enzymes, and genes of similar relation from Dd3937and Ds2222 were oligogalacturonate lyase encoded in the genes DDA3937_RS11450 and DSOIPO2222_RS11150, respectively. Neither Bacillus species utilized in the current study shared any similar enzymes or genes in the pectin degradation I pathway to the Dickeya species.

The pectin degradation pathway I shared by the Dickeya species degrades pectin to $\mathrm{D}$ galactopyranuronate +4 -deoxy-Lthreo-hex-4-enopyranuronate (Figure 4A). Pectin is degraded to pectate via pectinesterase $A$ in the metabolic reaction catalyzed by EC 3.1.1.11, with methanol byproduct (Figure 4B). Pectate is degraded to $\alpha-\mathrm{D}, \alpha-\mathrm{D}$-digalacturonate via several exo-poly$\alpha$-D-galacturonosidases in the metabolic reaction catalyzed by EC 3.2.1.82 with a pectate byproduct (Figure 4C). The $\alpha-D$,
$\alpha$-D-digalacturonate is degraded to $\mathrm{D}$ galactopyranuronate +4 deoxy-L-threo-hex-4-enopyranuronate in the metabolic pathway catalyzed by EC 4.2.2.- in $\operatorname{Dd} 3937$ via oligogalacturonate lyase (Figure 4D).

\section{DISCUSSION}

As pectinase is a vital enzyme utilized in the degradation of different fruit and vegetable products, it has value to the food industry (Sharma et al., 2013). Likewise, based on consumer preference, poultry industry diets are increasingly becoming vegetable-based void of animal protein (Weil, 2017). To make all-vegetable diets commercially viable, the poultry industry will need additional sources of feed grade pectinases with different hydrolytic capabilities to break down vegetable products with widely different compositional levels and subsequently improve broiler performance. Therefore, the utilization of a more flexible set of supplementary enzymes will become increasingly crucial to poultry nutritionists in enhancing the nutrient uptake in all-vegetable diets.

However, as D. dadantii has been reported to be a pathogen to plants and insects, another potential strategy for use of D. dadantii DSM 18020 pectinase genes would be to incorporate them into a current commercial poultry probiotic. Therefore, the genes of pectin degrading enzymes of Dd18020 could be inserted into a Bacillus, a known probiotic currently utilized in poultry diets. A Bacillus spp. would be a suitable candidate as they have the potential to withstand feed manufacturing conditions due to spore forming capabilities and can be genetically modified for industrial use (Ricke and Saengkerdsub, 2015). Though it is feasible, the insertion of Gram-negative genes ( $D$. dadantii) into a Gram-positive organisms (Bacillus) is not easily accomplished as it requires proper plasmid origin recognition, promoter recognition, and codon usage between the organisms. Another limitation to consider is that certain Bacillus species such as $B$. subtilis produce proteases that have been known to hinder the production of heterologous proteins (Puohiniemi et al., 1992). As such, the meticulous insertion of Gramnegative genes into Bacillus spp. has been possible through plasmid insertion (Luchansky et al., 1988; Ohta et al., 2005) and more recently through CRISPR-Cas9 systems (Toymentseva and Altenbuchner, 2019).

In the current study, data demonstrated that $D$. dadantii DSM 18020 possessed several pectinase-related enzymes such as polygalacturonases $(\mathrm{PG})$, pectin lyase $(\mathrm{PL})$, polygalacturonate lyase (PGL), and pectinesterase or pectin methylesterase (PE) (Sharma et al., 2013). The optimal pH for most endo PG, PL, PGL, and PEs are 2.5-6.0, 4.0-7.0, 6.0-11.0, and 4.0-7.0, respectively (Sharma et al., 2013). The optimal temperatures range from 30 to $50^{\circ} \mathrm{C}$ (PGs) and $40-60^{\circ} \mathrm{C}$ (PEs) (Sharma et al., 2013). The internal body temperature of poultry is $41.5^{\circ} \mathrm{C}$ (Dawson and Whittow, 2000 ) and the $\mathrm{pH}$ of the avian gastrointestinal tract (GIT) varies from highly acidic (below 4) in the proventriculus and gizzard and neutral in the lower intestines (above 7; Sturkie, 1999). 
Therefore, these enzymes should function as the avian GIT is within the optimal parameters for enzyme utilization.

In fact, the in vitro evaluation of PG and pectin methylesterase (PME) demonstrated an improvement in the digestion of pectin and a reduction in the water holding capacity of lupins in comparison to PG or PME alone (Ali et al., 2005). Therefore, Ali et al. (2005) concluded that the inclusion of legumes such as lupin could be increased by utilizing the combination of the two pectinases in poultry diets. Furthermore, the supplementation of pectinase with either cellulase or hemicellulase in corn-soybean meal broiler diets from days 15 to 27 has demonstrated the improvement in the ileal digestibility of crude protein (CP) and organic matter and increased apparent metabolizable energy content of the diet (Tahir et al., 2006). Other researchers have also found the supplementation of a multi-enzyme preparation with pectinase improved CP digestibility (Marsman et al., 1997; Kocher et al., 2002; Saleh et al., 2005). The improvement in CP digestibility may in part be due to the degradation and subsequent digestion of pectic polysaccharides (Slominski and Campbell, 1990; Simbaya et al., 1996). Due to $10 \%$ of the protein being entrapped in the cell wall matrix of soybeans, the degradation of the cell wall via the utilization of pectinase-related enzymes may release the contained proteins (Chesson, 2001). Also, half of the NSP's contained within the cell matrix of the soybean meal are pectic polysaccharides (Chesson, 2001). Their subsequent depolymerization may improve CP digestibility, which has been noted previously (Tahir et al., 2006).

\section{CONCLUSION}

The current study validates the genetic potential of $D$. dadantii DSM 18020 as an enzymatic pectinase producer to utilize commercially within the poultry feed industry. The results demonstrated that several pectin-related enzymes are encoded in the genome of $D$. dadantii, and $D$. dadantii possesses the most significant number of pectin degradation-related pathways. Also, the study demonstrates the genomic capability for metabolic breakdown of pectin via the pectin degradation pathway belonging to $D$. dadantii; however, further studies are necessary to evaluate the capabilities of $D$. dadantii DSM 18020 as a source of commercially viable pectinase for large scale production.

\section{REFERENCES}

Aguilar, G., and Huirton, C. (1990). Constitutive exo-pectinase produced by Aspergillus sp. CH-Y-1043 on different carbohydrate source. Biotechnol. Lett. 12, 655-660. doi: 10.1007/bf01088189

Albertsen, M., Hugenholtz, P., Skarshewski, A., Nielsen, K. L., Tyson, G. W., and Nielsen, P. H. (2013). Genome sequences of rare, uncultured bacteria obtained by differential coverage binning of multiple metagenomes. Nat. Biotechnol. 31, 533-538. doi: 10.1038/nbt.2579

Ali, A., Williams, I. H., Martin, G. B., and Sipsas, S. (2005). "Hydrolysis of lupin pectin by pectinases for broilers," in Proceedings of the 17th Annual Australian Poultry Science Symposium (Sydney: University of Sydney), 219-222.

Altschul, S. F., Gish, W., Miller, W., Myers, E. W., and Lipman, D. J. (1990). Basic local alignment search tool. J. Mol. Biol. 215, 403-410.
For example, more in-depth knowledge of pectin degradation by $D$. dadantii is necessary to quantify the pectinase production of D. dadantii to design scale up production. Based on the current in silico research study, $D$. dadantii does appear to produce pectinases that can further enhance the utilization of poultry diets and the continual supplementation via production by poultry probiotics fed to poultry may enhance nutrient absorption and subsequent performance. In relation to poultry, further analyses are necessary to determine if the supplementation of $D$. dadantii pectin-related enzymes in poultry diets is feasible. Some caution should be exercised as diet manufacturing involves steam and high temperature; this could potentially denature these key enzymes, thus reducing the effectiveness of pectin-related enzymes. Therefore, further research evaluating the survival of pectinases in poultry diets is necessary.

\section{DATA AVAILABILITY STATEMENT}

The datasets generated for this study can be found in the NCBI, Dickeya dadantii DSM 18020 (NZ_CP023467.1), D. dadantii 3937 (NC_014500.1), D. solani IPO 2222 (NZ_CP015137.1), Bacillus subtilis subsp. subtilis str. 168 (NC_000964.3) and B. halodurans C-125 (NC_002570.2).

\section{AUTHOR CONTRIBUTIONS}

DD wrote the manuscript with the assistance from SR, RB, and MR. All authors significantly contributed to the work of the current manuscript.

\section{ACKNOWLEDGMENTS}

DD would like to acknowledge the Graduate College at the University of Arkansas for its support of the research and the stipend provided through the Distinguished Academy Fellowship and the continued support from the Center for Advanced Surface Engineering, under the National Science Foundation Grant No. OIA-1457888 and the Arkansas EPSCoR Program, ASSET III. We would like to acknowledge Elena Olson for her assistance on the current manuscript.

Bailoni, L., Schaivon, S., Pagnin, G., Tagliapietra, F., and Bonsembiante, M. (2005). Quanti-qualitative evaluation of pectins in the dietary fibre of 24 foods. Ital. J. Anim. Sci. 4, 49-58. doi: 10.4081/ijas.2005.49

Barabote, R. D., Johnson, O. L., Zetina, E., San Francisco, S. K., Fralick, J. A., and San Francisco, M. J. D. (2003). Erwinia chrysanthemi tolC Is Involved in resistance to antimicrobial plant chemicals and is essential for phytopathogenesis. J. Bacteriol. 185, 5772-5778. doi: 10.1128/jb.185.19.57725778.2003

Barbe, V., Cruveiller, S., Kunst, F., Lenoble, P., Meurice, G., Sekowska, A., et al. (2009). From a consortium sequence to a unified sequence: the Bacillus subtilis 168 reference genome a decade later. Microbiology 155(Pt 6), 1758-1775. doi: 10.1099/mic.0.027839-0

Belda, E., Sekowska, A., Le Fevre, F., Morgat, A., Mornico, D., Ouzonis, C., et al. (2013). An updated metabolic view of the Bacillus subtilis 168 genome. Microbiology 159(Pt 4), 757-770. doi: 10.1099/mic.0.064691-0 
Borriss, R., Danchin, A., Harwood, C. R., Medigue, C., Rocha, E. P. C., Sekowska, A., et al. (2018). Bacillus subtilis, the model Gram-positive bacterium: 20 years of annotation refinement. Microb. Biotechnol. 11, 3-17. doi: 10.1111/1751-7915. 13043

Broz, J., and Beardsworth, P. (2002). "Recent trends and future developments in the use of feed enzymes in poultry nutrition," in Poultry Feedstuffs: Supply, Composition, and Nutritive Value, eds J. M. McNab, and K. N. Boorman, (Wallingford: CABI Publishing), 345-361. doi: 10.1079/9780851994642.0345

Buchanan, N. P., Hott, J. M., Kimbler, L. B., and Moritz, J. S. (2007). Nutrient composition and digestibility of organic broiler diets and pasture forages. J. Appl. Poult. Res. 16, 13-21. doi: 10.1093/japr/16.1.13

Burkholder, W. H. (1957). "Genus VI. Erwinia Winslow et al. 1917," in Bergey's Manual of Determinative Bacteriology, 7th Edn, eds R. S. Breed, E. G. D. Murray, and N. R. Smith, (Baltimore, MD: Williams \& Wilkins), 349-359.

Caspi, R., Altman, T., Billington, R., Dreher, K., Foerster, H., Fulcher, C. A., et al. (2014). The MetaCyc Database of metabolic pathways and enzymes and the BioCyc collection of Pathway/Genome Databases. Nucleic Acids Res. 42, D459-D471.

Cheng, Y., Yan, Z., Gao, C., Yu, Y., Li, Z., Zen, L., et al. (2017). Complete Genome Sequence of the Emerging Pathogen for Southern Economic Crops, Dickeya Secpp 1600. Changsha: Institute of Bast Fiber Crops and Center of Southern Economic Crops.

Chesson, A. (2001). Non-starch polysaccharide degrading enzymes in poultry diets: influence of ingredients on the selection of activities. Worlds Poult. Sci. J. 57, $252-263$.

Darling, A. C. E., Mau, B., Blattner, F. R., and Perna, N. T. (2004). Mauve: multiple alignment of conserved genomic sequence with rearrangements. Genome Res. 14, 1394-1403. doi: 10.1101/gr.2289704

Darling, A. C., Mau, B., and Perna, N. T. (2010). progressiveMauve: multiple genome alignment with gene gain, loss and rearrangement. PLoS One 5:e11147. doi: 10.1371 /journal.pone.0011147

Dawson, W. R., and Whittow, G. C. (2000). “Thermoregulation," in Sturkie's Avian Physiology, ed. G. C. Whittow, (San Diego, CA: Academic Press), 323-390.

Galperin, M. Y. (2015). Genome diversity of spore-forming Firmicutes. Microbiol. Spectr. 1:TBS-0015-2012. doi: 10.1128/microbiolspectrum.TBS-0015-2012

Garg, G., Singh, A., Kaur, A., Singh, R., Kaur, J., and Mahajan, R. (2016). Microbial pectinases: an ecofriendly tool of nature for industries. Biotech 6:47. doi: 10 . 1007/s13205-016-0371-4

Glasner, J. D., Yang, C. H., Reverchon, S., Hugouvieux-Cotte-Pattat, N., Condemine, G., Bohin, J. P., et al. (2011). Genome sequence of the plantpathogenic bacterium Dickeya dadantii 3937. J. Bacteriol. 193, 2076-2077. doi: 10.1128/JB.01513-10

Grenier, A. M., Duport, G., Pagès, S., Condemine, G., and Rahbé, T. (2006). The phytopathogen Dickeya dadantii (Erwinia chrysanthemi 3937) is a pathogen of the pea aphid. Appl. Environ. Microbiol. 72, 1956-1965. doi: 10.1128/AEM.72.3. 1956-1965.2006

Hugouvieux-Cotte-Pattat, N., Condemine, G., Nasser, W., and Reverchon, S. (1996). Regulation of pectinolysis in Erwinia chrysanthemi. Annu. Rev. Microbiol. 50, 213-257. doi: 10.1146/annurev.micro.50.1.213

Iverson, V., Morris, R. M., Frazar, C. D., Berthiaume, C. T., Morales, R. L., and Armbrust, E. V. (2012). Untangling genomes from metagenomes: revealing an uncultured class of marine Euryarchaeota. Science 335, 587-590. doi: 10.1126/ science. 1212665

Jayani, R. S., Saxena, S., and Gupta, R. (2005). Microbial pectinolytic enzymes: a review. Process Biochem. 40, 2931-2944. doi: 10.1016/j.procbio.2005.03.026

Junwei, C., Weihua, S., Yong, P., and Shuyun, C. (2000). High-producers of polygalacturonase selected from mutants resistant to rifampin in alkalophilic Bacillus sp. NTT33. Enzyme Microb. Technol. 27, 545-548. doi: 10.1016/S01410229(00)00200-3

Kamnev, A. A., Colina, M., Rodrigues, J., Ptitchkina, N. M., and Ignatov, V. V. (1998). Comparative spectroscopic characterization of different pectins and their sources. Food Hydrocoll. 12, 263-271. doi: 10.1016/s0268-005x(98)00 014-9

Khayi, S., Chong, T.-M., Helias, V., Chan, K.-G., and Faure, D. (2016). .Complete Genome Sequence of Dickeya solani type Strain IPO2222. Gif Sur Yvette: Institute for Integrative Biology of the Cell.

Kim, J. C., Mullan, B. P., Nicholls, R. R., and Pluske, J. R. (2011). Effect of Australian sweet lupin (Lupinus angustifolius L.) inclusion levels and enzyme supplementation on the performance, carcass composition and meat quality of grower/finisher pigs. Anim. Prod. Sci. 51, 37-43. doi: 10.1071/AN10087

King, K. (1993). Pectin: an untapped natural resource. Food Sci. Tech. 7, 147-152.

Kobayashi, T., Higaki, N., Suzumatsu, A., Sawada, K., Hagihara, H., Kawai, S., et al. (2001). Purification and properties of a high molecular-weight, alkaline exopolygalacturonase from a strain of Bacillus. Enzyme Microb. Technol. 29, 70-75. doi: 10.1016/S0141-0229(01)00355-6

Kocher, A., Choct, M., Porter, M. D., and Broz, J. (2002). Effects of feed enzymes on nutritive value of soybean meal fed to broilers. Br. Poult. Sci. 43, 54-63. doi: 10.1080/00071660120109890

Kumar, S., Stecher, G., Li, M., Knyaz, C., and Tamura, K. (2018). MEGA X: molecular evolutionary genetics analysis across computing platforms. Mol. Biol. Evol. 35, 1547-1549. doi: 10.1093/molbev/msy096

Kunst, F., Ogasawara, N., Moszer, I., Albertinim, A. M., Alloni, G., Azevedo, V., et al. (1997). The complete genome sequence of the Gram-positive bacterium Bacillus subtilis. Nature 390, 249-256.

Leeson, S. (2008). Prediction for commercial poultry nutrition. J. Appl. Poult. Res. 17, 315-322. doi: 10.3382/japr.2007-00101

Lockwood, S., Brayton, K. A., Daily, J. A., and Broschat, S. L. (2019). Whole proteome clustering of 2,307 proteobacterial genomes reveals conserved proteins and significant annotation issues. Front. Microbiol. 10:383. doi: 10. 3389/fmicb.2019.00383

Luchansky, J. B., Muriana, P. M., and Klaenhammer, T. R. (1988). Application of electroporation for transfer of plasmid DNA to Lactobacillus, Lactococcus, Leuconostoc, Listeria, Pediococcus, Bacillus, Staphylococcus, Enterococcus and Propionibacterium. Mol. Microbiol. 2, 637-646. doi: 10.1111/j.1365-2958.1988. tb00072.x

Marsman, G. J. P., Gruppen, H., Van der Poel, A. F. B., Kwakkel, R. P., Verstegen, M. W. A., and Voragen, A. G. J. (1997).The effect of thermal processing and enzyme treatments of soybean meal on growth performance, ileal nutrient digestibilities, and chyme characteristics in broiler chicks. Poult. Sci. 76, 864872. doi: $10.1093 / \mathrm{ps} / 76.6 .864$

Nakasome, K., Masui, N., Takaki, Y., Sasaki, R., Maeno, G., Sakiyama, T., et al. (2000). Characterization and comparative study of the rrn operons of alkaliphilic Bacillus halodurans C-125. Extremophiles 4, 209-214. doi: 10.1007/ pl00010713

Ohta, Y., Hatada, Y., Ito, S., and Horikoshi, K. (2005). High-level expression of a neoagarobiose-producing $\beta$-agarase gene from Agarivorans sp. JAMB-A11 in Bacillus subtilis and enzymic properties of the recombinant enzyme. Biotechnol. Appl. Biochem. 41, 183-191. doi: 10.1042/BA20040083

O’Leary, N. A., Wright, M. W., Brister, J. R., Ciufo, S., Haddad, D., McVeigh, R., et al. (2016). Reference sequence (RefSeq) database at NCBI: current status, taxonomic expansion, and functional annotation. Nucleic Acids Res. 44(D1), D733-D745. doi: 10.1093/nar/gkv1189

Pédron, J., Mondy, S., des Essarts, Y. R., Van Gijsegem, F., and Faure, D. (2014). Genomic and metabolic comparison with Dickeya dadantii 3937 reveals the emerging Dickeya solani potato pathogen to display distinctive metabolic activities and T5SS/T6SS-related toxin repertoire. BMC Genom. 15:283. doi: 10.1186/1471-2164-15-283

Pierson, E. E. M., Potter, L. M., and Brown, R. D. (1980). Amino acid digestibility of dehulled soybean meal by adult turkeys. Poult. Sci. 59, 355-360.

Piknik, W. (1990). Gums and Stabilisers for the Food Industry 5. Oxford: IRL Press, 209-221.

Puohiniemi, R., Simonen, M., Muttilainen, S., Himanen, J. -P., and Sarvis, M. (1992). Secretion of the E. coli outer membrane proteins OmpA and OmpF in Bacillus subtilis is blocked at an early intracellular step. Mol. Microbiol. 6, 981-990. doi: 10.1111/j.1365-2958.1992.tb02164.x

Ravirala, R. S., Barabote, R. D., Wheeler, D. M., Reverchon, S., Tatum, O., Malouf, J., et al. (2007). Efflux pump gene expression in Erwinia chrysanthemi is induced by exposure to phenolic acids. Mol. Plant Microbe Interact. 20, 313-320. doi: 10.1094/mpmi-20-3-0313

Ricke, S. C., Van Der Aar, P. J., Fahey, G. C., Jr., and Berger, L. L. (1982). Influence of dietary fibers on performance and fermentation characteristics of gut contents from growing chicks. Poult. Sci. 61, 1335-1343. doi: 10.3382/ps.0611335

Ricke, S.C., and Saengkerdsub, S. (2015). "Bacillus probiotics and biologicals for improving animal and human health: current applications and future prospects," in Beneficial Microbes in Fermented and Functional Foods, eds R. V. Ravishankar, and J. A. Bai, (Boca Raton, FL: CRC Press), 341-360. 
Sakai, T. (1992). "Degradation of pectins," in Microbial Degradation of Natural Products, ed. G. Winkelmann, (Weinheim: Wiley-VCH Verlag GmbH \& Co. KGaA), 57-81.

Saleh, F., Tahir, M., Ohtsuka, A., and Hayashi, K. (2005). A mixture of pure cellulase, hemicellulase and pectinase improves broiler performance. Br. Poult. Sci. 46, 602-606. doi: 10.1080/00071660500255661

Samson, R., Legendre, J. B., Christen, R., Fischer-Le Saux, M., Achouak, W., and Garden, L. (2005). Transfer of Pectobacterium chrysanthemi (Burkholder et al. 1953) Brenner et al. 1973 and Brenneria paradisiaca to the genus Dickeya gen. nov. as Dickeya chrysanthemi comb. nov. and Dickeya paradisiaca comb. nov. and delineation of four novel species, Dickeya dadantii sp. nov., Dickeya dianthicola sp. nov., Dickeya dieffenbachiae sp. nov. and Dickeya zeae sp. Nov. Int. J. Syst. Evol. Microbiol. 55, 1415-1427. doi: 10.1099/ ijs.0.02791-0

Selvendran, R. R. (1985). Developments in the chemistry and biochemistry of pectic and hemicellulosic polymers. J. Cell Sci. 1985(Suppl. 2), 51-88. doi: 10.1242/jcs.1985.supplement_2.4

Sharma, N., Rathore, M., and Sharma, M. (2013). Microbial pectinase: sources, characterization, and applications. Rev. Environ. Sci. Biotechnol. 12, 45-60. doi: 10.1007/s11157-012-9276-9

Sharon, I., Morowitz, M. J., Thomas, B. C., Costello, E. K., Relman, D. A., and Banfield, J. F. (2013). Time series community genomics analysis reveals rapid shifts in bacterial species, strains, and phage during infant gut colonization. Genome Res. 23, 111-120. doi: 10.1101/gr.142315.112

Simbaya, J., Slominski, B. A., Guentery, W., Morgan, A., and Campbell, L. D. (1996). The effect of protease and carbohydrase supplementation on the nutritive value of canola meal for poultry-in vitro and in vivo studies. Anim. Feed Sci. Technol. 61, 219-234.

Slominski, B. A., and Campbell, L. D. (1990). Non-starch polysaccharides of canola meal: quantification, digestibility in poultry and potential benefit of dietary enzyme supplementation. J. Agric. Food Chem. 53, 175-184.

Sturkie, P. D. (1999). Avian Physiology, 5th Edn. San Diego, CA: Academic Press, 301-314.

Tahir, M., Saleh, F., Ohtsuka, A., and Hayashi, K. (2006). Pectinase plays an important role in stimulating digestibility of a corn-soybean meal in broiler diets. J. Poult. Sci. 43, 323-329.

Tahir, M., Saleh, F., Ohtsuka, A., and Hayashi, K. (2005). Synergistic effect of cellulase and hemicellulase on nutrients utilization and performance in broilers fed corn-soybean meal diet. Anim. Sci. J.76, 559-565. doi: 10.1111/j.1740-0929. 2005.00304.x

Takami, H., and Horikoshi, K. (2000). Analysis of the genome of an alkaliphilic Bacillus strain from an industrial point of view. Extremophiles 4, 99-108. doi: 10.1007/s007920050143

Takami, H., Nakasone, K., Takaki, Y., Maeno, G., Sasake, R., Masui, N., et al. (2000). Complete genome sequence of the alkaliphilic bacterium Bacillus halodurans and genomic sequence comparison with Bacillus subtilis. Nucleic Acids Res. 28, 4317-4331. doi: 10.1093/nar/28.21.4317
Thompson, J. D., Higgins, D. G., and Gibson, T. J. (1994). CLUSTAL W: improving the sensitivity of progressive multiple sequence alignment through sequence weighting, position-specific gap penalties and weight matrix choice. Nucleic Acids Res.22, 4673-4680. doi: 10.1093/nar/22.22.4673

Toth, I. K., Bell, K. S., Holeva, M. C., and Birch, P. R. J. (2003). Soft rot erwiniae: from genes to genomes. Mol. Plant Pathol. 4, 17-30. doi: 10.1046/j.1364-3703. 2003.00149.x

Toth, I. K., van der Wolf, J. M., Saddlerm, G. Lojkowska, E., Hélias, V. Pirhonen, M., Tsror, L., and Elphinstone, J. G. (2011). Dicheya species: an emerging problem for potato production in Europe. Plant Pathol. 60, 385-399. doi: 10. 1111/j.1365-3059.2011.02427.x

Toymentseva, A. A., and Altenbuchner, J. (2019). New CRISPR-Cas9 vectors for genetic modifications of Bacillus species. FEMS Microbiol. Lett. 366:fny284. doi: 10.1093/femsle/fny284

Tyson, G. W., Chapman, J., Hugenholtz, P., Allen, E. E., Ram, R. J., and Richardson, P. M. et al. (2004). Community structure and metabolism through reconstruction of microbial genomes from the environment. Nature 428, 37-43. doi: $10.1038 /$ nature 02340

Visser, J., Bussink, H. J., and Witteveen, C. (2004). Gene Expression in Recombinant Microorganisms, ed. A. Smith, (New York, NY: Marcel Dekker, Inc), 241-306.

Wagner, D. D., and Thomas, O. P. (1977). A rye type growth depression of chicks fed pectin. Poult. Sci. 56, 615-619. doi: 10.3382/ps.0560615

Wagner, D. D., and Thomas, O. P. (1978). Influence of diets containing rye or pectin on the intestinal flora of chicks. Poult. Sci. 57, 971-975. doi: 10.3382/ ps.0570971

Weil, J. T. (2017). Evaluating the Impact of an All-Vegetable Protein Supplement Containing Fat Emulsifiers and Probiotics on Broiler Performance. Ph.D. thesis, University of Arkansas, Fayetteville, AR.

Whitaker, J. R. (1991). Microbial Enzymes and Biotechnology, eds C. T. Kelly, and W. M. Fogarty, (London: Elsevier), 133-175.

Wrighton, K. C., Thomas, B. C., Sharon, I., Miller, C. S., Castelle, C. J., and VerBerkmoes, N. C. et al. (2012). Fermentation, hydrogen, and sulfur metabolism in multiple uncultivated bacterial phyla. Science 337, 1661-1665. doi: 10.1126/science.1224041

Yadav, S., Yadav, P. K., Yadav, D., and Yadav, K. D. S. (2009). Pectin lyase: a review. Process Biochem. 44, 1-10. doi: 10.1016/j.procbio.2008.09.012

Conflict of Interest: The authors declare that the research was conducted in the absence of any commercial or financial relationships that could be construed as a potential conflict of interest.

Copyright (c) 2020 Dittoe, Barabote, Rothrock and Ricke. This is an open-access article distributed under the terms of the Creative Commons Attribution License (CC BY). The use, distribution or reproduction in other forums is permitted, provided the original author(s) and the copyright owner(s) are credited and that the original publication in this journal is cited, in accordance with accepted academic practice. No use, distribution or reproduction is permitted which does not comply with these terms. 